\title{
Article
}

\section{Nanocrystalline titanium dioxide catalyst for the synthesis of azlactones}

\author{
Priyanka Anandgaonker, Ganesh Kulkarni, Suresh Gaikwad, Anjali Rajbhoj* \\ Department of Chemistry, Dr. Babasaheb Ambedkar Marathwada University, Aurangabad 431004 (MS), India
}

\section{A R T I C L E I N F O}

\section{Article history:}

Received 25 August 2013

Accepted 21 October 2013

Published 20 February 2014

\section{Keywords:}

Nanocrystalline titanium dioxide

Electrochemical reduction method

Cyclodehydration-condensation

Heterogeneous catalyst

\begin{abstract}
A B S T R A C T
Titanium dioxide nanoparticles were prepared by a electrochemical reduction method using parameters such as current density, solvent polarity, distance between electrodes, and concentration of stabilizers to control the size of the nanoparticles. The nanoparticles were characterized by UV-Vis spectroscopy, X-ray diffraction, scanning electron microscopy and transmission electron microscopy, and their catalytic performance was tested for the synthesis of a series of 4-aryldiene-2-phenyl-5(4)-oxazolones from the cyclodehydration and condensation of the respective aldehyde, hippuric acid and acetic anhydride. Easy availability, reusability and eco-friendliness were some prominent features of the nanocrystalline titanium dioxide catalyst.
\end{abstract}

(C) 2014, Dalian Institute of Chemical Physics, Chinese Academy of Sciences. Published by Elsevier B.V. All rights reserved.

\section{Introduction}

During the past few decades, many results were published in the area of the synthesis of heterocyclic molecules whose physical and chemical properties make them biologically important [1]. Among these, 2-oxazolin-5-ones (azlactones) are multifunctional compounds that are known to react at the $\mathrm{C}=\mathrm{C}$, $\mathrm{C}=\mathrm{N}, \mathrm{C}=\mathrm{O}$ bonds, and so they are important for the synthesis of many natural products, synthetic intermediates and pharmaceuticals [2-4]. They are also useful precursors for the synthesis of unsaturated amino acids [5], peptides [6] and biosensors [7]. Substituted oxazole derivatives have been found to be useful for their biological activity such as antibacterial [8], antitubercular [9], anticancer [10] and antitumor [11] activity. Other application of oxazole derivatives includes their use as fluorescent whitening agents, lubricants, dyes and pigments [12-15].

The most common method for their preparation is the Erlenmeyer-Plöchl reaction which proceeds by the cyclodehydration and condensation of the aldehyde and hippuric acid in dry acetic anhydride catalyzed by sodium acetate [16]. The classical reaction has remained unchanged for the last century with only some modernization in the reagents and catalysts, such as the use of supported $\mathrm{KF}$ [17], $\mathrm{Bi}(\mathrm{OAc})_{3}$ [18], $\mathrm{Bi}(\mathrm{OTF})_{3}$ [19], [bmim] $\mathrm{OH}$ [20], $\mathrm{Ca}(\mathrm{OAc})_{2}$ [21], ZnO NPs[22], alumina [23], $\mathrm{KPO}_{4}$ [24] or a sonochemical reaction [25]. Each of these advances has its own merits, but they also suffer from drawbacks such as reaction at high temperature, unsatisfactory yields, harsh reaction conditions, and use of stoichiometric amounts of catalyst. Thus the development of a new synthesis strategy which can overcome these drawbacks using an easily accessible catalyst is still important.

Metal nanoparticles are promising materials as the heterogeneous catalyst in a variety of organic transformations [26-30]. Their catalytic properties are functions of their size and crystal lattice parameters and they show amazing levels of performance in terms of selectivity, activity and improved yield of products [31-33]. In particular, titanium dioxide nanoparticles exhibited many special properties because the band gap of the nanoparticles increased with the decrease in size. The

* Corresponding author. Tel: +91-240-2403311; Fax: +91-240-2403335; E-mail: anjali.rajbhoj@gmail.com 
use of $\mathrm{TiO}_{2}$ nanoparticles has received considerable attention in green synthetic organic chemistry [34-38] and the photo-degradation of carcinogenic dyes [39] and pesticides [40].

The synthesis of transition metal nanoparticles by the electrochemical reduction method was originally reported by Reetz et al [41], who showed that it gave metal nanoparticles with a narrow size distribution. The cluster size was found to decrease with an increase in current density [42]. The solid product exhibited electronic, paramagnetic, optical and catalytic properties that were significantly better than those of the bulk material, which was due to its extremely small size and large surface area. In the present work, $\mathrm{TiO}_{2}$ nanoparticles were prepared by the electrochemical reduction method and their catalytic activity was tested for the synthesis of azlactone.

\section{Experimental}

\subsection{Catalyst preparation}

All chemicals were purchased from Aldrich and S. D. Fine Chemicals Suppliers and used as received. The purity of the substrates and the reaction monitoring were determined by thin layer chromatography (TLC) and visualization under ultraviolet (UV) light. In the initial experiment we used a titanium metal sheet $(1 \mathrm{~cm} \times 1 \mathrm{~cm})$ as anode and a platinum sheet $(1 \mathrm{~cm}$ $\times 1 \mathrm{~cm}$ ) as the cathode. The two electrodes were $1 \mathrm{~cm}$ apart. Tetrabutyl ammonium bromide (TBAB, $0.01 \mathrm{~mol} / \mathrm{L}$ ) in an acetonitrile and tetrahydrofuran solution (4:1) was the electrolyte. Upon applying a current density of $10 \mathrm{~mA} / \mathrm{cm}^{2}$, we obtained > $95 \%$ of the titanium dioxide clusters getting stabilized by TBAB. Electrolysis was carried out in nitrogen atmosphere. The titanium dioxide nanoparticles were white in color. Since the material was insoluble in the solvent used, the work up only needed simple decantation. The decanted solid product was washed with dry THF three to four times to remove excess tetrabutyl ammonium bromide and dried in a vacuum desiccator. The dried sample was calcined at $550{ }^{\circ} \mathrm{C}$ and stored in closed glass vials under ambient conditions.

\subsection{Catalyst characterization}

The titanium dioxide nanoparticles were characterized by UV-Vis spectrophotometry, XRD, TEM, and SEM-EDS techniques. The wavelength of absorbance was determined by a UV-Vis spectrophotometer [JASCO 503] using a quartz cuvette and an acetonitrile/tetrahydrofuran solution as reference. The IR spectra were recorded on a FT-IR spectrometer [JASCO, FT-IR/4100, Japan] using dry $\mathrm{KBr}$ as the standard reference. The XRD patterns of the $\mathrm{TiO}_{2}$ nanoparticles were recorded on a Bruker 8D advance X-ray diffractometer using $\mathrm{Cu} K_{\alpha}$ radiation of wavelength $0.154056 \mathrm{~nm}$. To study the morphology of $\mathrm{TiO}_{2}$ nanoparticles, SEM analysis was carried out with a JEOL (JSM-6330 LA) equipment operated at $20.0 \mathrm{kV}$ and $1.0 \mathrm{nA}$. The elemental compositions of the $\mathrm{TiO}_{2}$ nanoparticles were examined using a energy dispersive spectrometer (EDS). The TEM analysis was carried out with a Philips Model CM200 equipment operated at $20-200 \mathrm{kV}$. ${ }^{1} \mathrm{H}$ NMR spectra were recorded on an $400 \mathrm{MHz}$ FT-NMR spectrometer with $\mathrm{CDCl}_{3}$ as a solvent. The chemical shift values are recorded as $\delta$ (ppm units) relative to tetramethylsilane $\left(\mathrm{Me}_{4} \mathrm{Si}\right)$ as an internal standard.

\subsection{Typical reaction procedure}

A mixture of an aromatic or heteroaromatic aldehyde (2 mmol), hippuric acid ( $2 \mathrm{mmol})$, acetic anhydride $(6 \mathrm{mmol})$ and $100 \mathrm{mg}$ of $\mathrm{TiO}_{2}$ nanoparticles in $5 \mathrm{ml}$ ethanol was heated with constant stirring at $120^{\circ} \mathrm{C}$. At first the mixture became almost solid and then with increase in temperature, it gradually turned into a deep yellow colored liquid. The progress of reaction was monitored by TLC. After completion of the reaction, $30 \mathrm{ml}$ of hot ethanol was added to the flask to separate out the catalyst. After cooling, the yellow color product was filtered and washed with ice cold ethanol and then with hot water, and dried and recrystallized to afford pure crystals of the desired compound. The products (3a-3m) were confirmed by comparison with standard samples using the IR, ${ }^{1} \mathrm{H}$ NMR and $\mathrm{C}^{13} \mathrm{NMR}$ spectra and melting points.

\subsection{Spectral data of representative compounds}

3a. Bright yellow needles. ${ }^{1} \mathrm{H}$ NMR $\left(\mathrm{CDCl}_{3}, \mathrm{ppm}\right) \delta=$ 8.22-8.17 (m, 4H, ArH), 7.55-7.61 (m, 3H, ArH), 7.22-7.39 (m, $3 \mathrm{H}, \mathrm{Ar}-\mathrm{H}$ and $-\mathrm{CH}=)$; ${ }^{13} \mathrm{C}$ NMR ( $\left.101 \mathrm{MHz}, \mathrm{CDCl}_{3}\right) \delta=110.0$, 125.6, 128.4, 128.8, 128.9, 131.2, 131.8, 132.4, 133.3, 133.5, 163.6, 167.6; IR (KBr) $v=3322,2930,1795,1655,1165 \mathrm{~cm}^{-1}$.

3c. Yellow needles. ${ }^{1} \mathrm{H}$ NMR (CDC1 $\left.13, \mathrm{ppm}\right) \delta=7.16(\mathrm{~s}, 1 \mathrm{H}$, $-\mathrm{CH}=$ ), 7.40-7.64 (m, 5H, Ar-H), 7.85 (d, 1H, Ar-H), 8.00 (d, 1H, Ar-H), 8.19 (d, 1H, Ar-H), 8.30 (s, 1H, Ar-H); ${ }^{13} \mathrm{C}$ NMR (101 MHz, $\left.\mathrm{CDCl}_{3}\right) \delta=125.39,128.06,128.58,129.01,129.87,131.12$, $31.25,131.70,134.02,134.42,135.84,190.25$; IR (KBr): $v=$ 3322, 2930, 1799, 1657, $1165 \mathrm{~cm}^{-1}$.

3f. Bright yellow solid. ${ }^{1} \mathrm{H}$ NMR $\left(\mathrm{CDCl}_{3}, \mathrm{ppm}\right) \delta=8.19-8.16$ $(\mathrm{m}, 2 \mathrm{H}), 8.10(\mathrm{~d}, J=8.1 \mathrm{~Hz}, 2 \mathrm{H}), 7.62-7.52(\mathrm{dd}, J=10.5 \mathrm{~Hz}, 4.6$, $2 \mathrm{H}), 7.28(\mathrm{~d}, J=8.0 \mathrm{~Hz}, 2 \mathrm{H}), 7.23(\mathrm{~s}, 1 \mathrm{H}), 2.42\left(\mathrm{~s}, 3 \mathrm{H}, \mathrm{CH}_{3}\right) ;{ }^{13} \mathrm{C}$ NMR $\left(101 \mathrm{MHz}, \mathrm{CDCl}_{3}\right) \delta=21.3,125.6,128.6,128.9,129.6$, 132.1, 132.3, 133.1, 133.3, 133.6, 139.0, 163.5, 167.7; IR (KBr) $v$ $=3432,2922,1791,1654,1160 \mathrm{~cm}^{-1}$.

3h. Orange solid. ${ }^{1} \mathrm{H}$ NMR $\left(\mathrm{CDCl}_{3}, \mathrm{ppm}\right) \delta=3.87\left(\mathrm{~s}, 3 \mathrm{H}, \mathrm{CH}_{3}\right)$, $7.12(\mathrm{~d}, 2 \mathrm{H}, J=8.4 \mathrm{~Hz}, \mathrm{ArH}), 7.35$ (s, 1H, $-\mathrm{CH}=)$, 7.62-7.74 (m, $3 \mathrm{H}, \mathrm{ArH}$ ), 8.12 (d, $2 \mathrm{H}, J=8.4 \mathrm{~Hz}, \mathrm{ArH}), 8.32(\mathrm{~d}, 2 \mathrm{H}, J=8.4 \mathrm{~Hz}$, ArH); IR (KBr) $v=3432,2938,1789,1654,1162 \mathrm{~cm}^{-1}$.

3g. Yellow needles. ${ }^{1} \mathrm{H}$ NMR $\left(\mathrm{CDCl}_{3}, \mathrm{ppm}\right) \delta=7.39(\mathrm{~d}, 1 \mathrm{H}, J=$ $7.6 \mathrm{~Hz}, \mathrm{ArH}), 7.48$ (s, 1H, $-\mathrm{CH}=$ ), 7.53-7.66 (m, 4H, ArH), 8.17(d, $2 \mathrm{H}, J=7.6 \mathrm{~Hz}, \mathrm{ArH}), 8.90(\mathrm{~d}, 1 \mathrm{H}, J=8.4 \mathrm{~Hz}, \mathrm{ArH})$; IR (KBr) $v=$ $3448,3088,1798,1658,1170 \mathrm{~cm}^{-1}$.

\section{Results and discussion}

\subsection{SEM-EDS results}

SEM analysis was carried out to study the morphology of the $\mathrm{TiO}_{2}$ nanoparticles. It can be seen from Fig. 1(a) that the $\mathrm{TiO}_{2}$ powders have a uniform size and can be classified as nanoparticles. The EDS spectrum was used to analyze the composition 

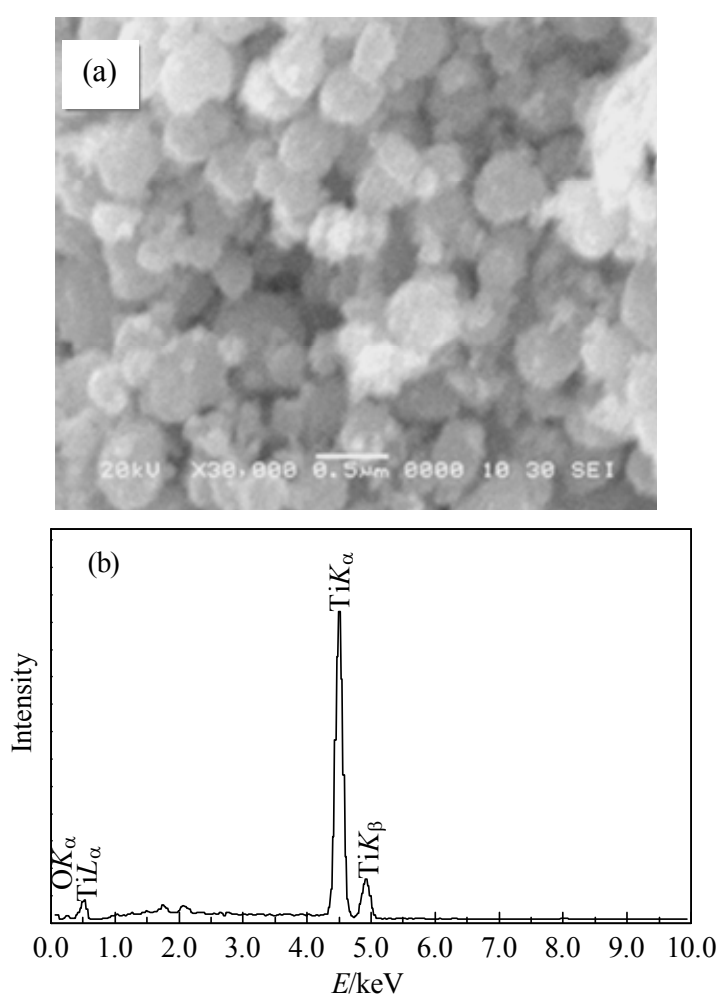

Fig. 1. (a) SEM and (b) EDS characterization of the $\mathrm{TiO}_{2}$ nanoparticles.

of the $\mathrm{TiO}_{2}$ nanoparticles. The result is shown in Fig. 1(b). The $\mathrm{Ti}$ and $\mathrm{O}$ peaks were clearly present in the spectrum and there was no other peak, which indicated that $\mathrm{TiO}_{2}$ particles were successfully synthesized by the electrochemical reduction method.

\subsection{UV-Vis spectra}

As the electrochemical reduction proceeded, the change in colour of the reaction mixture with time was monitored. It was seen that between 15 to 20 min a change in color took place. The spectra were recorded after every 30 min reaction. In Fig. 2 , the UV-Vis absorbance spectra showed that the intensity of the characteristic band at $344 \mathrm{~nm}$ increased with time, which indicated the formation of titanium dioxide nanoparticles with the anatase phase.

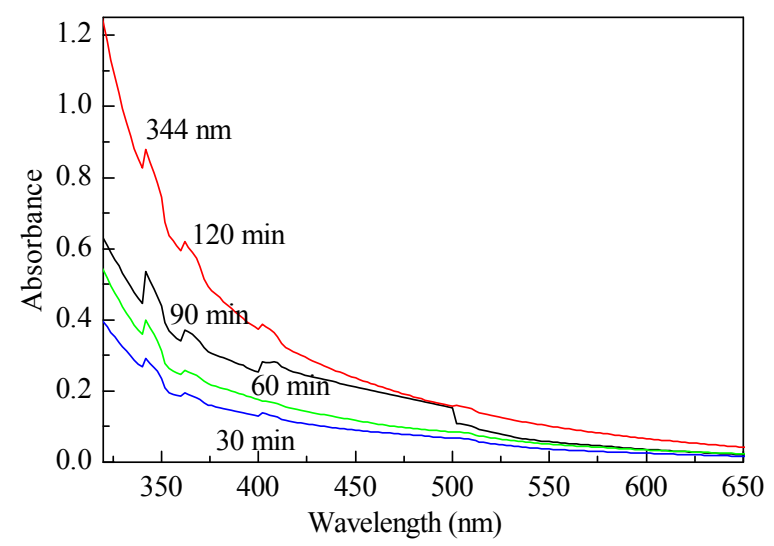

Fig. 2. UV-vis spectra of the $\mathrm{TiO}_{2}$ nanoparticles.

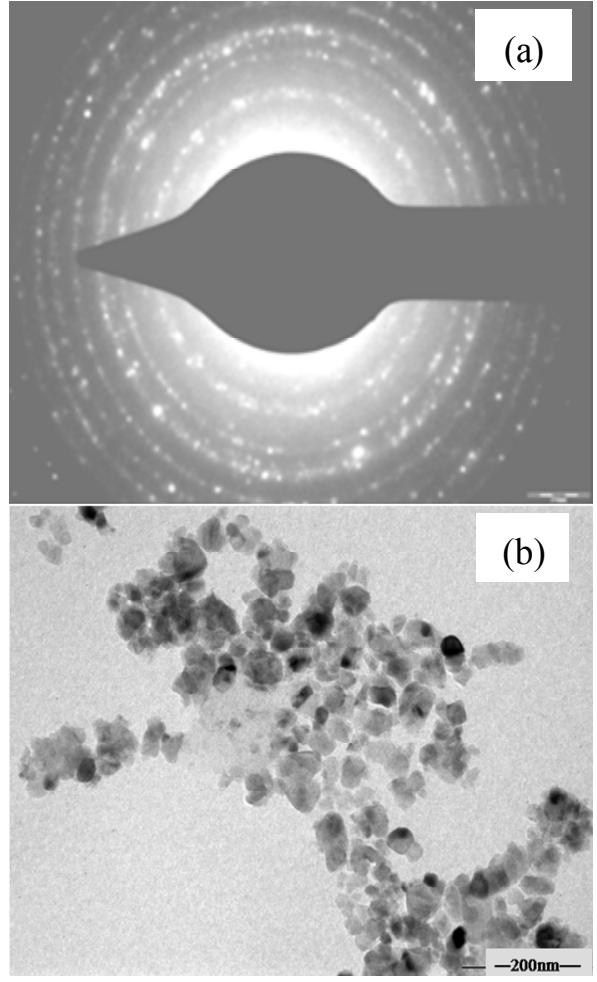

Fig. 3. SAED pattern (a) and TEM image (b) of the $\mathrm{TiO}_{2}$ nanoparticles.

\subsection{TEM characterization}

TEM analysis was carried to examine the particle size, crystallinity and morphology of the sample. The sample for TEM analysis was prepared by the evaporation of very dilute alcoholic suspensions onto carbon-coated copper grids. The magnified image in Fig. 3 showed that the particles were well dispersed and no aggregation was observed. The particles have a tetragonal shape with sizes of 25-30 nm.

\subsection{XRD characterization}

In Fig. 4, the peaks corresponding to the (101), (004), (200), (105), (204), (220), and (215) planes with the lattice parameters $a=b=3.780$ and $c=9.513$ indicated the formation of $\mathrm{TiO}_{2}$ nanoparticles with the anatase phase. All the peaks were in

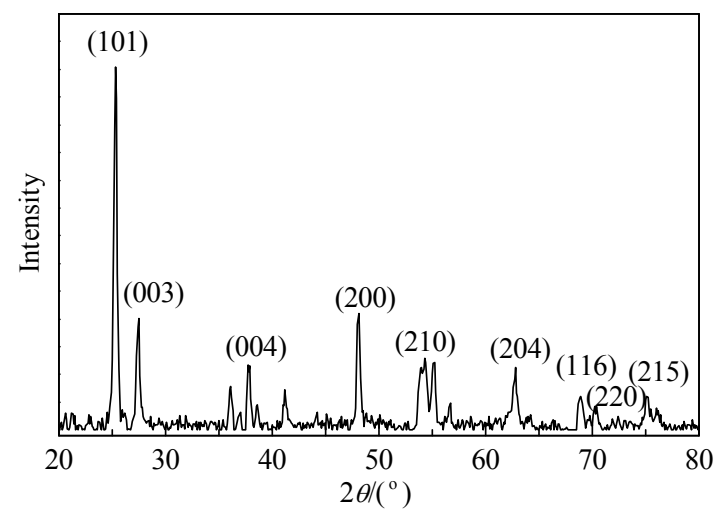

Fig. 4. XRD pattern of the $\mathrm{TiO}_{2}$ nanoparticles. 


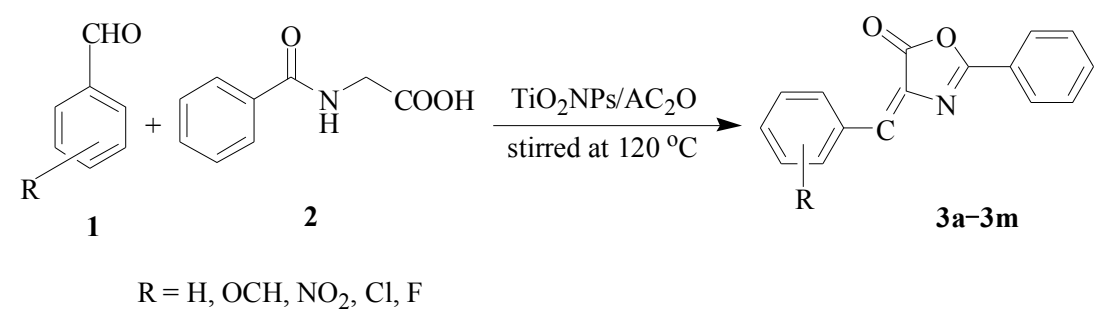

Scheme 1. Synthesis of 4-aryldiene-2-phenyl-5(4)-oxazolones derivatives catalyzed by $\mathrm{TiO}_{2} \mathrm{NPs}_{\text {. }}$

good agreement with JCPDS card no. 86-1156. The $\mathrm{TiO}_{2}$ had a pure tetragonal crystal phase structure. The particle size was calculated from the X-ray line broadening and full width at half maximum (FWHM) using the Debye-Scherrer equation $D=$ $0.94 \lambda / \beta \cos \theta$, where $D$ is particle size, $\lambda$ is wavelength, $\theta$ is diffraction angles, and $\beta$ is FWHM. The average particle size was found to be $25.63 \mathrm{~nm}$.

\subsection{Catalytic activity}

Our literature survey showed that the Erlenmeyer reaction is affected by the acid as well as the base and only scant literatures are available for this reaction. Thus we would like to report the present protocol of the use of $\mathrm{TiO}_{2}$ nanoparticles for the synthesis of 4-aryldiene-2-phenyl-5(4)-oxazolones by reacting aldehyde 1, hippuric acid 2, acetic anhydride in $5 \mathrm{ml}$ of ethanol with constant stirring and heating at $120^{\circ} \mathrm{C}$ as shown in Scheme 1. Both aromatic aldehydes with an electron-donating or electron-withdrawing group as well as a heterocyclic system such as Furan-2-carboxyaldehyde reacted smoothly to produce high yields of the products. The results with different aromatic aldehydes are summarized in Table 1.

We also evaluated the amount of catalyst required for the reaction. We found that the yields were obviously affected by the amount of catalyst loading. We investigated the model reaction of benzaldehyde, hippuric acid and acetic anhydride using

\section{Table 1}

Synthesis of 4-aryldiene-2-phenyl-5(4)-oxazolones derivatives catalyzed by $\mathrm{TiO}_{2} \mathrm{NPs}$.

\begin{tabular}{lccccc}
\hline \multirow{2}{*}{ Product a } & \multirow{2}{*}{$\mathrm{R}$} & \multirow{2}{*}{$\begin{array}{c}\text { Time } \\
\text { (min) }\end{array}$} & $\begin{array}{c}\text { Yield } \\
\text { (\%) }\end{array}$ & \multicolumn{2}{c}{ Melting point $\left({ }^{\circ} \mathrm{C}\right)$} \\
\hline $\mathbf{3 a}$ & $\mathrm{C}_{6} \mathrm{H}_{5}$ & 30 & 95 & $169-170$ & $170-172[20]$ \\
$\mathbf{3 b}$ & $4-\mathrm{ClC}_{6} \mathrm{H}_{4}$ & 25 & 96 & $185-187$ & $187-188[20]$ \\
$\mathbf{3 c}$ & $3-\mathrm{ClC}_{6} \mathrm{H}_{4}$ & 35 & 95 & $155-156$ & $156-157[19]$ \\
$\mathbf{3 d}$ & $4-\mathrm{NO}_{2} \mathrm{C}_{6} \mathrm{H}_{4}$ & 30 & 94 & $242-243$ & $240-241[23]$ \\
$\mathbf{3 e}$ & $3-\mathrm{NO}_{2} \mathrm{C}_{6} \mathrm{H}_{4}$ & 25 & 96 & $163-164$ & $166-167[20]$ \\
$\mathbf{3 f}$ & $4-\mathrm{CH}_{3} \mathrm{C}_{6} \mathrm{H}_{4}$ & 35 & 95 & $144-145$ & $141-143[23]$ \\
$\mathbf{3 g}$ & $2,4-\mathrm{Cl}_{2} \mathrm{C}_{6} \mathrm{H}_{3}$ & 40 & 92 & $159-160$ & $160-162[19]$ \\
$\mathbf{3 h}$ & $4-\mathrm{MeC}_{6} \mathrm{H}_{4}$ & 45 & 93 & $155-156$ & $155-157[23]$ \\
$\mathbf{3 i}$ & $\mathrm{C}_{6} \mathrm{H}_{6} \mathrm{COCH}_{3}$ & 40 & 94 & $104-106$ & $105-106[23]$ \\
$\mathbf{3 j}$ & $2-\mathrm{furfural}_{3}$ & 50 & 93 & $169-170$ & $170-171[20]$ \\
$\mathbf{3 k}$ & $4-\mathrm{FC}_{6} \mathrm{H}_{4}$ & 35 & 95 & $170-171$ & $169-170[20]$ \\
$\mathbf{3 l}$ & $4-\mathrm{BrC}_{6} \mathrm{H}_{4}$ & 40 & 92 & $196-197$ & $195-196[18]$ \\
$\mathbf{3 m}$ & $\mathrm{C}_{6} \mathrm{H}_{5} \mathrm{CH}_{4}=\mathrm{CH}$ & 40 & 93 & $128-129$ & $130-131[20]$ \\
\hline $\mathbf{2}$
\end{tabular}

a Reaction conditions: aldehyde $(2 \mathrm{mmol})$, hippuric acid $(2 \mathrm{mmol})$, acetic anhydride $(6 \mathrm{mmol})$ and $100 \mathrm{mg}$ of $\mathrm{TiO}_{2}$ nanoparticles in $5 \mathrm{ml}$ ethanol stirred at $120^{\circ} \mathrm{C}$.
Table 2

Screening of catalyst ( $\left.\mathrm{TiO}_{2} \mathrm{NPs}\right)$ concentration for the synthesis of $4 \mathbf{a}$.

\begin{tabular}{lccc}
\hline Entry & Catalyst amount $(\mathrm{mg})$ & Time $(\mathrm{min})$ & ${\text { Yield }(\%)^{\text {a }}}$ \\
\hline 1 & 50 & 120 & 35 \\
2 & 70 & 120 & 67 \\
3 & 90 & 90 & 89 \\
4 & 100 & 30 & 95 \\
5 & 120 & 30 & 96 \\
\hline
\end{tabular}

Table 3

Recycle of $\mathrm{TiO}_{2} \mathrm{NPs}$ in the synthesis of 4 a.

\begin{tabular}{lcccc}
\hline Run & Fresh & 1 & 2 & 3 \\
\hline Yield (\%) & 95 & 95 & 94 & 92 \\
\hline
\end{tabular}

different amounts of catalyst from 50 to $120 \mathrm{mg}$. The best yield was obtained using $100 \mathrm{mg}$ catalyst. With even more catalyst, the yield of the desired product was found to be constant. We also carried out the reaction without any catalyst, but the product was isolated in poor yield $(10 \%)$ and the starting material was recovered. Therefore, the catalyst plays a crucial role in the success of the reaction in term of the yields of the product. The results obtained are summarized in Table 2 .

In this study, the catalyst was recovered and reused. The catalyst was recovered by a simple work-up using centrifugation, and then it was washed with ethanol and reused. This was done for three successive runs, which gave yields of the product that were almost the same as that in the first run. This is shown in Table 3.

\section{Conclusions}

We demonstrated a mild, simple and green procedure for the synthesis of 4-aryldiene-2-phenyl-5(4)-oxazolones using recyclable $\mathrm{TiO}_{2}$ nanoparticles. The catalyst promoted the yields and shortened the reaction time. The catalyst showed excellent stable activity during three recycle runs. The ease of work-up and the clean procedure will make the present method a useful and important method for the synthesis of azlactones.

\section{Acknowledgments}

The Department of Chemistry of Dr. Babasaheb Ambedkar Marathwada University, Aurangabad acknowledges the financial assistance of the UGC-SAP-DRS-1 Scheme, New Delhi. ASR is thankful for the financial assistance from the UGC Major Research Project, New Delhi. 


\section{Graphical Abstract}

Chin. J. Catal., 2014, 35: 196-200 doi: 10.1016/S1872-2067(12)60741-4

\section{Nanocrystalline titanium dioxide catalyst for the synthesis of azlactones}

Priyanka Anandgaonker, Ganesh Kulkarni, Suresh Gaikwad, Anjali Rajbhoj* Dr. Babasaheb Ambedkar Marathwada University, India

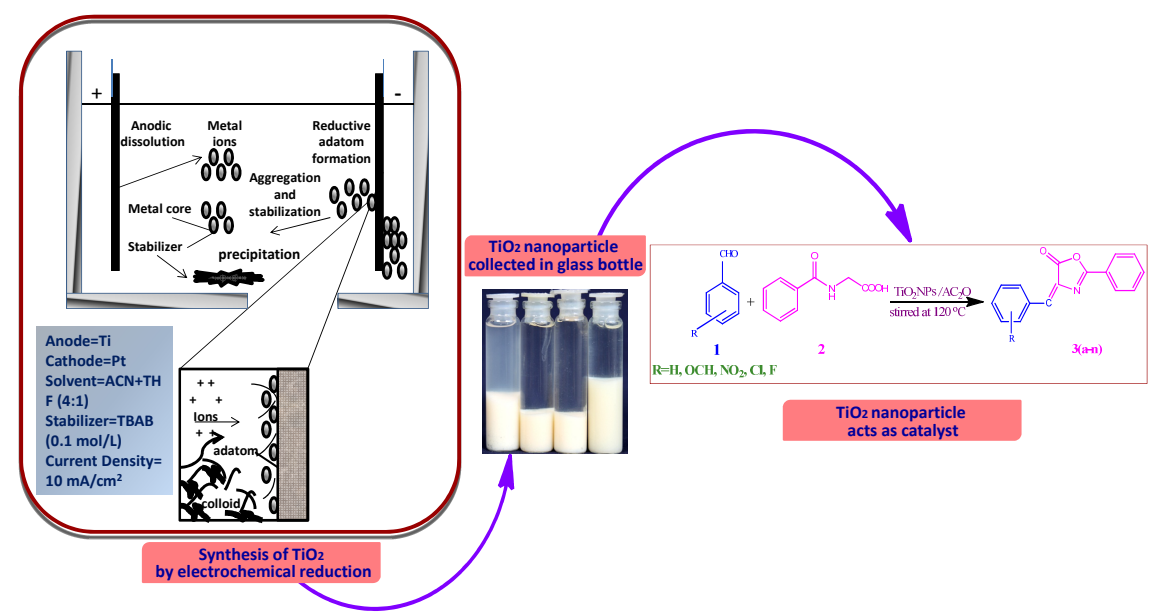

Size controlled synthesis of $\mathrm{TiO}_{2}$ by electrochemical reduction gave nanoparticles for the synthesis of 4-aryldiene-2-phenyl-5(4)-oxazolones. The smaller size catalyst has promising features for the reaction.

\section{References}

[1] Keay B A, Dibble P W. In: Bird CW II ed. Comprehensive Heterocyclic Chemistry. New York: Elsiver, 1996. 395

[2] Jin Z. Nat Prod Rep, 2003, 20: 584

[3] Wipf P. Chem Rev, 1995, 95: 2115

[4] Avenoza A, Busto J H, Cativiela C, Peregrina J M. Tetrahedron Lett, 2002, 43: 4167

[5] Konkel J T, Fan J F, Jayachandran B, Kirk K L. J Fluore Chem, 2002, 115: 27

[6] Cavelier F, Verducci J. Tetrahydron Lett, 1995, 36: 4425

[7] Kojima S, Ohkawa H, Hirano T, Maki S, Niwa H, Ohashi M, Inouye S, Tsuji F I. Tetrahydron Lett, 1998, 39: 5239

[8] Tsuji K, Ishikawa H. Bioorg Med Chem Lett, 1994, 4: 1601

[9] Giddens A C, Boshoff H I M, Franzblau S G, Barry C E III, Copp B R. Tetrahedron Lett, 2005, 46: 7355

[10] Gottwald K, Seebach D. Tetrahydron, 1999, 55: 723

[11] Penalva J, Puchades R, Maquieira A, Gee S, Hammock B D. Biosens Bioelectron, 2000, 15: 99

[12] Yeh V S C. Tetrahedron, 2004, 60: 11995

[13] Hamada Y, Shioiri T. Chem Rev, 2005, 105: 4441

[14] Dabholkar V V, Parab S D. Indian J Chem, 2007, 46B: 344

[15] Dabholkar V V, Mishra S K J. Indian J Chem, 2006, 45B: 2112

[16] Beccalli E M, Clerici F, Gelmi M L. Tetrahydron, 1999, 55: 781

[17] Bautista F M, Campelo J M, Garcia A, Luna D, Marinas J M, Romero A A. J Chem Soc, Perkin Trans 2, 2002, (2): 227

[18] Monk K A, Sarapa D, Mohan R S. Synth Commun, 2000, 30: 3167

[19] Jamor H, Jabar S. J Chem Res Synop, 2003, (10): 638

[20] Patil S G, Bagul R R, Kamble V M, Navale V A. J Chem Pharm Res, 2011, 3(4): 285

[21] Paul S, Nanda P, Gupta R, Loupy A. Tetrahydron Lett, 2004, 45:
425

[22] Päsha M A, Jayäshankara V P, Venugopala K N, Rao G K. J Pharmacol Toxicol, 2007, 2(3): 264

[23] Conway P A, Devine K, Paradisi F. Tetrahedron, 2009, 65: 2935

[24] Cleary T, Brice J, Kennedy N, Chavez F. Tetrahedron Lett, 2010, 51: 625

[25] Heravi M R P. J Univ Chem Technol Metallurgy, 2009, 44: 86

[26] Ornelas C, Mery D, Blais J C, Cloutet E, Aranzaes J R, Astruc D. Angew Chem Int Ed, 2005, 44: 7399

[27] Ranu B C, Chattopadhyay K. Org Lett, 2007, 9: 2409

[28] Polshettiwar V, Varma R S. Org Biomol Chem, 2009, 7: 37

[29] Mitsudome T, Mikami Y, Mori H, Arita S, Mizugaki T, Jitsukawa K, Kaneda K. Chem Commun, 2009: 3258

[30] Singh P, Kumari K, Katyal A, Kalra R, Chandra R. Catal Lett, 2009, 127: 119

[31] Astruc D. Inorg Chem, 2007, 46: 1884

[32] Djakovitch L, Koehler K, deVries J G. In: Astruc D ed. Nanoparticles and Catalsis. 2008. 303

[33] Durand J, Teuma E, Gomez M. Eur J Inorg Chem, 2008, (23): 3577

[34] Kantam M L, Laha S, Yadav J, Sreedhar B. Tetrahedron Lett, 2006, 47: 6213

[35] Ropero-Vega J L, Aldana- Péreza A, Gómez R, Ninó-Gómez M E. Appl Catal A, 2010, 379: 24

[36] Kassaee M Z, Mohammadi R, Masrouri H, Movahedi F. Chin Chem Lett, 2011, 22: 1203

[37] Farhad S, Vahid A S, Meysam A K. Iran J Catal, 2011, 1: 93

[38] Abdolmohammadi S. Chin Chem Lett, 2012, 23: 1003

[39] Tariq M A, Faisal M, Muneer M. J Hazard Mater, 2005, 127: 172

[40] Mahalakshmi M, Arabindoo B, Palanichamy M, Murugesan V. J Hazard Mater, 2007, 143: 240

[41] Reetz M T, Helbig W. J Am Chem Soc, 1994, 116: 7401

[42] Borgohain K, Murase N, Mahamuni S. J Appl Phys, 2002, 92: 1292 